\title{
Soil thermal conductivity from early TRT logs using an active hybrid optic fibre system
}

\section{Antonio Galgaro Matteo Cultrera}

\author{
Philippe Pasquier \\ Giorgia Dalla Santa*
}

\author{
Luca Schenato
}

\begin{abstract}
At the Molinella test site in Italy, a monitoring well has been equipped with a bybrid active optical fibre cable down to the depth of $100 \mathrm{~m}$ sealed with geothermal grouting. The cored borehole provided a full stratigraphic sequence of unconsolidated alluvial deposits. The cored material has been classified from a geotechnical point of view, and the thermal parameters of the most relevant lithologies have been directly measured. Active heating of the optical fibre cable has been provided by a constant heating power injected through copper wires contained within the cable structure. This way, not only the equivalent thermal conductivity of the entire stratigraphy but also the thermal conductivity at a spatial resolution of $1 \mathrm{~m}$ have been obtained. For each investigated layer, the thermal conductivity obtained from the distributed temperature measurements and the ones acquired using direct measurements are interpreted and compared.
\end{abstract}

\section{INTRODUCTION}

Ground Source Heat Pumps (GSHP) are well-established systems for building conditioning, thanks to their high energy efficiency (Lucia et al., 2017). The closed-loop ground borehole heat exchanger (BHE) is the most widely used configuration for heating and cooling purposes (Sarbu and Sebarchievici, 2014). One of the most relevant elements in the design phase of GSHP systems is the knowledge of the thermal parameters of the geological materials crossed by the BHE; hence, the local thermal exchange capacity can be evaluated to finally calculate the required total borehole length. An overestimation or an underestimation of the thermal exchange capacity of the ground could strongly affect the installation and running costs of the ground heat exchanger as well as the energetic efficiency of the whole heating and cooling system over the years.

The local thermal exchange capacity can be obtained in several ways (Vieira et al., 2017); (I) by assuming the thermal parameters reported in literature for each sediment (VDI 4640, 2010); (II) by measuring thermal conductivity and capacity directly on the materials cored on-site (Popov et al., 1999; Tarnawski et al., 2013; Dalla Santa et al., 2017); (III) from the data acquired by a Thermal Response Tests (TRT) performed on site. The method (I) requires the availability of a detailed stratigraphic sequence for the installation site for which the evaluation could be incorrect because the thermal properties of a specific soil can vary greatly and differ from the ones reported in literature due to the variability of the geological conditions (consolidation status, moisture content and saturation, compaction level, etc.) as well as to the sediment's mineralogical composition. The (II) method requires the coring of the well and the

Antonio Galgaro (antonio.galgaro@unipd.it) is a professor of Geothermal Systems at Geosciences Department of Università degli Studi di Padova. Philippe Pasquier (philippe.pasquier@polymtl.ca) is a professor of geological engineering at Polytechnique Montréal (Canada).

Luca Schenato (luca.schenato@cnr.it) is a researcher of the Research Institute for Geo-Hydrological Protection at the National Research Council. Matteo Cultrera (matteo.cultrera@gmail.com) is a research fellow at the Geosciences Department of Università degli Studi di Padova (Italy).

Giorgia Dalla Santa (giorgia.dallasanta@unipd.it, corresponding author) is a research fellow at the Civil, Environmental And Architectural Engineering (ICEA) Department and at the Department of Geosciences of Università degli Studi di Padova (Italy). 
sampling of each deposit to be measured directly. Moreover, the direct measurement of the samples thermal properties could be affected by some scale effects and neglects the contribution of the advection heat transfer processes in the aquifers.

Among the three methods, only the TRT-based one provides the undisturbed temperature of the ground and an equivalent thermal conductivity of the system, which is affected by the entire stratigraphy sequence, the local hydrogeological conditions as well as by the borehole thermal behaviour (heat-carrier fluid, pipes and sealing grout). A TRT is carried out by injecting/extracting heat to/from the BHE at a constant power and measuring the thermal response of the ground (Gehlin and Spitler, 2001). The system and the testing procedure were established by the American Society of Heating, Refrigerating and Air-Conditioning Engineers (ASHRAE) (Gehlin and Nordell, 2003). Conventional TRT performed on closed-loop ground heat exchangers requires the use of a specific TRT unit and the procedure is time-consuming and, therefore, expensive.

Hence, with the purpose of evaluating the ground thermal properties at a lower cost and with a higher spatial and temporal resolution, the Distributed Thermal Response Test (DTRT) has been recently developed (Vieira et al., 2017). This new technique is performed by means of a hybrid cable integrating some copper wires and a bundle of fibre optics, sealed into the well (see fig.2a, fig. 2c). The DTRT allows the measurement of the vertical ground temperature distribution along the entire length of the borehole with high spatial and temporal resolution.

A hybrid optical fibre cable has been sealed into a borehole down to the depth of $100 \mathrm{~m}$ in the field laboratory of Molinella (Italy) with the purpose of testing the DTRT. The thermal conductivity data (related to the most relevant lithologies) directly measured by means of a portable device on the cored samples, combined with a geotechnical classification of the cored deposits, have been compared to the interpretation of the DTRT temperature profile obtained along the well with a spatial resolution of 1 meter after a very short (about 5 hours) heating period. This paper introduces the preliminary results and shows that the data acquired from the DTRT are able to identify the thermal conductivity profile and the geological layers variability. Therefore, by means of DTRT a significant reduction of the ground thermal testing time and - consequently - of the costs of the overall investigations can be expected.

\section{METHODS}

\section{The test site}

The test site is located in Molinella, between the city of Ferrara and Bologna in the Po Plain (Galgaro et al., 2017), which is the largest alluvial plain in Western Europe (Fig. 1a). The geological setting of the site is typical of lowland areas, consisting of unconsolidated sediments.

The $100 \mathrm{~m}$ deep well coring of the test site has been collected in specific catalogue boxes. During the coring, the water table was $1.5 \mathrm{~m}$ below the ground level. The geotechnical classification of the deposits provided the complete local stratigraphy of unconsolidated fluvial sediments. The lithological sequence can be described as a dominantly horizontally layered structure, typical of a quaternary floodplain deposition environment, dominated by silt and silty clay deposits alternated with thin sandy layers, as shown in Fig.1b. Recent studies have highlighted that these kinds of sediments can display settlements and permeability alterations when exposed to significant temperature variations (Dalla Santa et al., 2016a and 2016b; Dalla Santa et al., 2018). No aquifers with significant water flow have been detected, due to the very low permeability of the deposits and to the very low hydraulic gradient.

\section{Direct thermal properties measurements on samples}

For the main recognized layers, the thermal properties (conductivity and capacity) have been directly measured on the collected core samples by a hand-held instrument ISOMET 2114-Thermal properties analyzer (Isomet, 2017) which applies a transient heat transfer by means of a probe placed in direct contact with the tested sediment. The probe contains both a resistor used as a heat source and a temperature sensor. The temperature response generated by each material to the transient heating signal induced by the electrical heater is recorded and analyzed, hence obtaining 
the thermal properties of the sample. The ISOMET measuring error declared by the producer is about $10 \%$. The procedure followed to perform the measurement follows ASTM standard recommendations (ASTM standard, 2008). The sedimentary sequence of the Molinella test site is reported in Galgaro et al. (2017) and Zarrella et al. (2017), while the measured values of thermal conductivity are reported in Fig. 4b. The measurements were performed on site, soon after the coring, to maintain the sediments natural water content.

a)

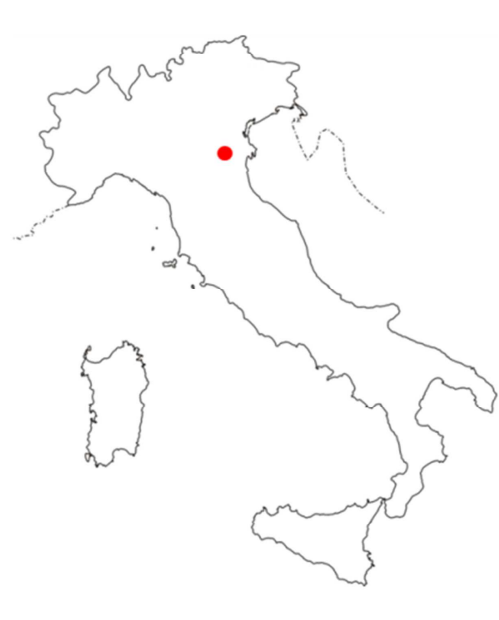

b)

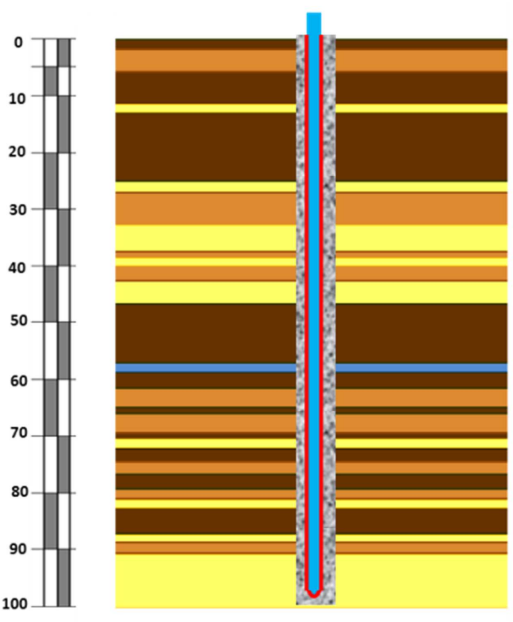

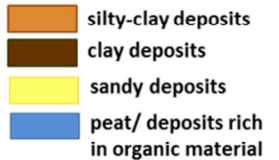

in organic material

Figure 1 a) The position of the Molinella test site in Italy and b) The schematic geological sequence.

\section{The DTRT with hybrid optical fibre cable}

After the drilling, a hybrid fibre optic cable composed of 4 copper wires and one bundle of 5 optical fibres has been sealed into the well with thermally enhanced grout with a thermal conductivity of $1.7 \mathrm{~W} / \mathrm{mK}$. Fig. 2 reports a schematic representation of the device and some pictures of the installation procedure.

The DTRT has been performed by heating the ground by means of the current injected into the copper wires (i.e. Joule effect), while the vertical ground temperature distribution has been measured by the optical fibres. The use of the optic fibre cable allows the acquisition of temperature profile along the entire length of the borehole, due to the signal emitted into the fibre and backscatterd through the acquisition system being sensitive to temperature, thus exploiting the Raman scattering occurring in optical fibres (Schenato, 2017). The working principle is quite simple; when an optical pulse is injected into a fibre, three signals are generated (I) the Rayleigh backscattered signal at the same wavelength of the input light, (II) the Stokes component at a longer wavelength, and (III) the anti-Stokes component at a shorter wavelength. In particular, only the anti-Stokes signal intensity is temperature-dependent (approximately $0.8 \% / \mathrm{K}$ at room temperature), while the Stokes is not. The ratio between the two intensities is, therefore, a measurement of the temperature at which the backscattered signals have been generated.

The use of Distributed Temperature Sensing (DTS) in thermal response testing allows measurements of high spatial (0.2-5m), temporal (1-10 min) and temperature (0.1-0.5K) resolution (Selker et al., 2006; Vieira et al., 2017). In this work, to perform the DTRT we used a commercial DTS interrogator by AP Sensing with sampling interval of $0.5 \mathrm{~m}$, spatial resolution of $1 \mathrm{~m}$ and a temperature repeatability of few tenths of a Kelvin degree.

The DTS has been firstly used without heating in order to collect the undisturbed temperature of the soil, that was around $14-15^{\circ} \mathrm{C}$. Then, the thermal solicitation of the well and the surrounding ground has been provided by injecting 
into the copper wires an almost constant heating power of $2630 \mathrm{~W}$ for about 5 hours. The heating power is assumed to be constant along the cable for its entire length (equal to $218 \mathrm{~m}$ ).

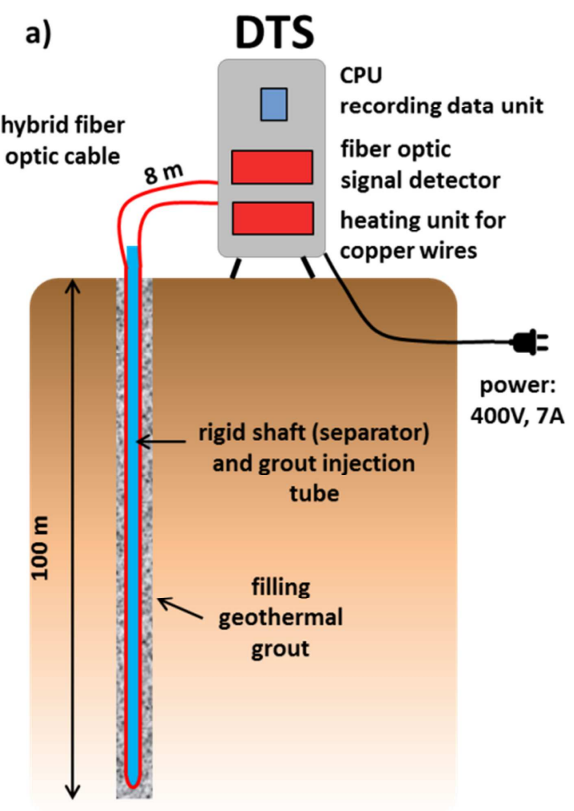

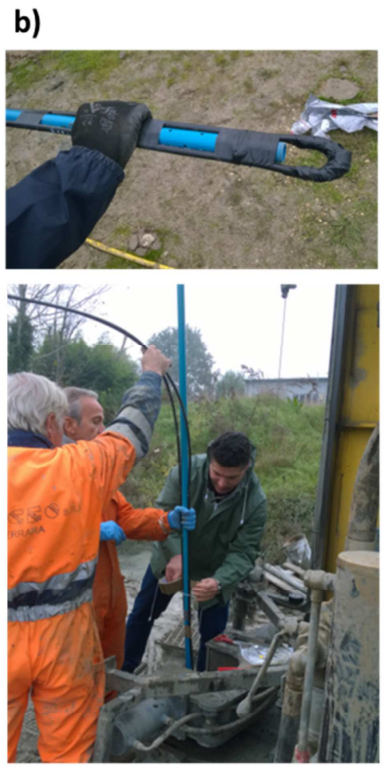

d) c)

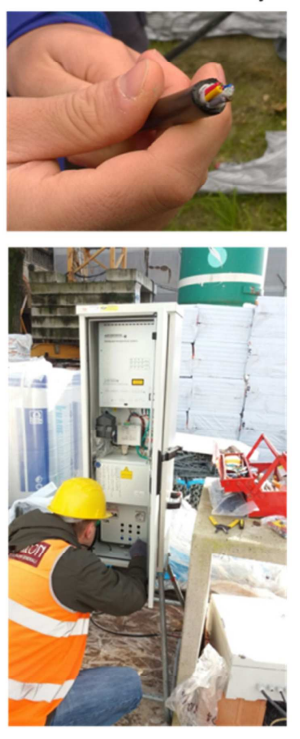

e)

Figure 2 (a) A schematic representation of the DTS and some pictures of the installation procedure: (b) detail of the hybrid cable U-loop to be installed at the bottom of the well to protect the cable; c) section of the hybrid fibre optic cable with the copper wires and the bundle of optic fibres; d) installation procedure, with the hybrid fibre optic cable clamped to a rigid shaft before the installation; e) the Distributed Temperature Sensing interrogator during the test.

During the DTRT, the temperature along the fibre optic cable has been recorded every two minutes during the heating period and the subsequent 4 days, to measure the recovery thermal phase of the ground. At the end of the 5hour heating test, the profile temperature was almost constant for the entire profile (around $25^{\circ} \mathrm{C}$ ). During the subsequent recovery phase, the temperature measured at different depths cooled down at different rates, depending on the thermal properties of the surrounding deposits.

Given that the hybrid fiber optic cable was deployed in the well in a looped configuration (duplexed), both the heating than the measuring systems consist in two parallel lines.

From the DTRT data analysis the effective thermal conductivity of the surrounding ground can be inferred, allowing differentiating layers characterized by different thermal behaviour and, therefore, different geological conditions.

The raw temperature data, staked in time to form a 2D-dataset, have been numerically filtered to reduce the noise using 2D-wavelet transform. This approach benefits the effectiveness of $2 \mathrm{D}$ image processing and it allows for improved signal-to-noise ratio in both dimensions, i.e., time and space, simultaneously. A more rigorous approach would consist in using the algorithm directly to the Stokes and Anti-Stokes signals intensity (Soto et al., 2016) but here it was not applicable as they were not available.

Fig. 3 shows a comparison of the raw and denoised data for a given trace and for the temporal evolution at a given depth. One can observe that, during the cooling phase, the temperature oscillates over time with amplitude of few tenths of ${ }^{\circ} \mathrm{C}$. A similar fluctuation is present at all depth and its origin is under investigation. 


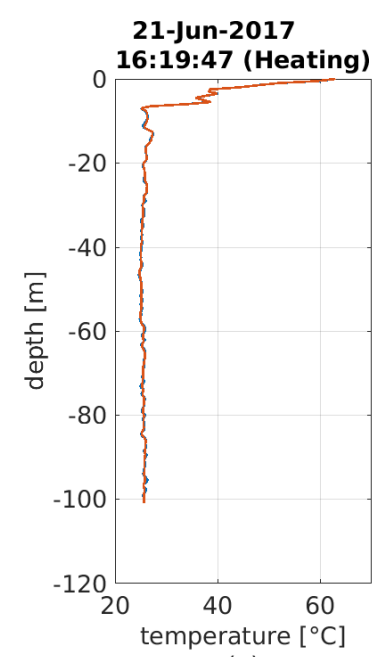

(a)
23-Jun-2017

18:17:42 (Cooling) 0

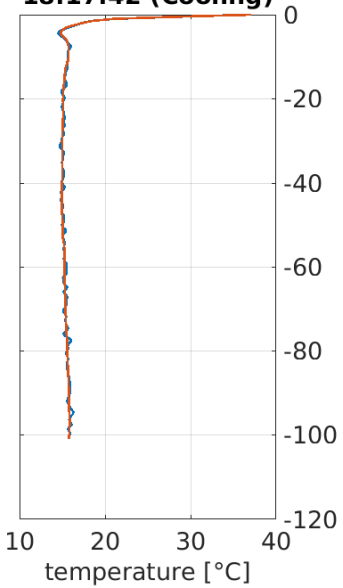

(b)

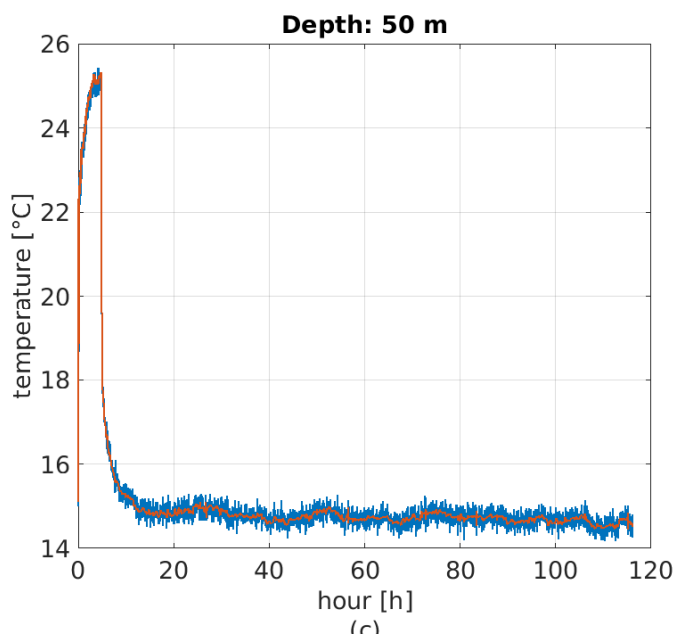

(c)

Figure 3 Raw data (blue) are compared with the denoised data (red curve) obtained by filtering with a biorthogonal wavelet. (a) Distributed temperature profile measured on June 21, 2017, 16:19:47 during the heating phase. (b) Distributed temperature profile measured on June 23, 2017, 18:17:42 during the cooling phase. (b) Temporal evolution of the temperature at $50 \mathrm{~m}$ of depth, during the heating and cooling phases.

\section{The analytical method}

TRTs performed on closed-loop ground heat exchangers are usually analyzed by the first-order approximation of the Infinite Line-Source model (Ingersoll et al, 1954). The traditional TRT interpretation strategy consists in fitting a linear regression model to the late average temperature data of the circulating fluid over time, after stimulating the soil with a thermal power approximately constant for a period of time long enough to ensure that the system will reach a thermal equilibrium. Being the obtained slope of the linear regression - that is the derivative of the mean temperature - related to the heating power and to the thermal properties of the surrounding ground, the method provides the value of the equivalent ground thermal conductivity (Gehlin and Spitler, 2001).

We used the same interpretation method to analyze the high spatial resolution temperature data acquired during the DTRT, by fitting a linear regression to the last part of temperature data measured at each depth along the cable, in order to infer the thermal conductivity of the surrounding deposit (see Fig.4a). Due to the U-loop shape of the hybrid cable, each ground layer is heated by two wires thermally interacting with each other.

The spatial superposition principle and Infinite Line-Source model can be used to interpret a TRT when two heat sources of infinite length, each emitting a heating power $q$, are close to each other. Using the first-order approximation of the Infinite Line-Source model to represent the temperature change around the heating wires allows to express the mean temperature measured by the optical fibres at a depth z through (Gehlin and Spitler, 2001):

$$
T(z, t)=T_{0}(z)+q R_{w}+\sum_{i=1}^{n} \frac{q}{4 \pi \lambda(z)}\left(\ln \left(\frac{4 \alpha t}{r_{i}^{2}}\right)-\gamma\right)
$$

Reorganizing the previous equation to highlight the link between the natural logarithm of time and the thermal conductivity $\lambda$ measured at a depth ₹ leads to: 


$$
T(z)=T_{0}(z)+q R_{w}+\frac{2 q}{4 \pi \lambda(z)} \ln (t)+\frac{q}{4 \pi \lambda(z)} \sum_{i=1}^{n}\left(\ln \left(\frac{4 \alpha}{r_{i}^{2}}\right)-\gamma\right)
$$

Finally, the thermal conductivity is provided for a case with two interacting heat sources by

$$
\lambda(z)=\frac{q}{2 \pi m(z)}
$$

where $m(z)$ is the regression coefficient obtained by a linear regression when using the logarithm of time as the regressor and the mean temperature measured by the two optical fibres as the dependent variable. By applying this procedure, we interpret the 200 temperature signals (one every $0.5 \mathrm{~m}$ ) acquired during the DTRT.

\section{RESULTS}

The early heating phase has been analysed with the analytical method described previously and applied to the denoised signals for every depth. From the registered variation of temperature along time, the thermal conductivity of the surrounding deposit has been inferred; Fig. 4a illustrates an example of the regression fit to one of the 200 experimental traces obtained during the DTRT. The thermal conductivity values calculated every $0.5 \mathrm{~m}$ were assembled together to provide the entire vertical profile illustrated in Fig. 4b. For comparison, Fig. 4b also shows the thermal conductivity data obtained from the measurements performed directly on the cored samples (represented with the red circles) and the stratigraphy. The following comments should be made:

1. The spatial resolution of the DTS interrogator $(1 \mathrm{~m})$, is twice the distance among sensing points $(0.5 \mathrm{~m})$. Hence, the thermal conductivity value inferred for each measurement point is correspondingly averaged over $1 \mathrm{~m}$ fiber optic cable.

2. On the other side, the values of thermal conductivity of each lithological layer have been obtained from the experimental measurements performed on site on the core in the halfway point of each recognized layer.

3. The DTRT was performed during very hot days at the end of June with a mean external air temperature of $30^{\circ} \mathrm{C}$, while the drilling and direct measurements on the samples were performed during a rainfall-heavy period of November soon after the drilling of the well.

While the thermal conductivities directly measured follow the stratigraphy succession (with higher values for sandy deposits and lower values for the cohesive ones), the profile obtained from the DTRT shows less concordance. It could be ascribed to the fact that the DTRT integrates a larger ground volume and performs a vertical spatial average of the signal including many influencing factors along the borehole.

For the shallower layers (less than $12 \mathrm{~m}$ ), the difference between the two series is higher and the profiles even seem inverted; this could be a consequence of different humidity conditions of the geological materials due to external factors such as air temperature and solar heating/dehydration. In the deeper deposits the thermal conductivity shows less variability.

The vertical dotted lines in Fig. 4b) represent the mean values for the thermal conductivity obtained with the DTRT (in blue, $1.47 \mathrm{~W} / \mathrm{mK}$ ) and with the direct measurements (in red) (equal to $1.30 \mathrm{~W} / \mathrm{mK}$, calculated as the average of $\lambda$ corresponding to each deposit weighted on the deposit thickness). The difference can be ascribed to scale effects such as the difference in the volume of soil involved in the thermal process used for the evaluation (Low et al., 2015). Due to the very short heating time, the volume of ground involved in the measurements is limited (less than $50 \mathrm{~cm}$ from the borehole wall). For this reason, also the penetration of the grout injected to seal the well in the geological formations may have affected the measurements. 
In addition, the values directly measured on the core may be underestimated with respect to the effective thermal conductivity on site because of the sample disturbance due to the loss in confining pressure after the sample was extracted, given that the higher the state of consolidation, the higher the thermal conductivity. In Fig $4 \mathrm{~b}$, the green pointed lines represent the global values of $\lambda$ obtained from a traditional TRT performed in a well with the same length at the same tests site by using different interpretation methods (as described in Zarrella et al, 2017). Both of the mean values presented in this paper are within the traditional TRT results.

a)

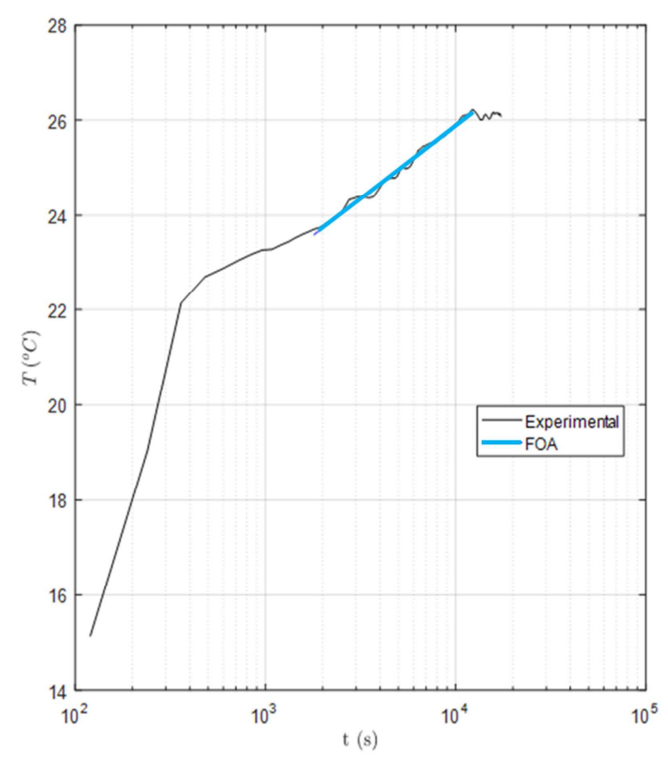

b)

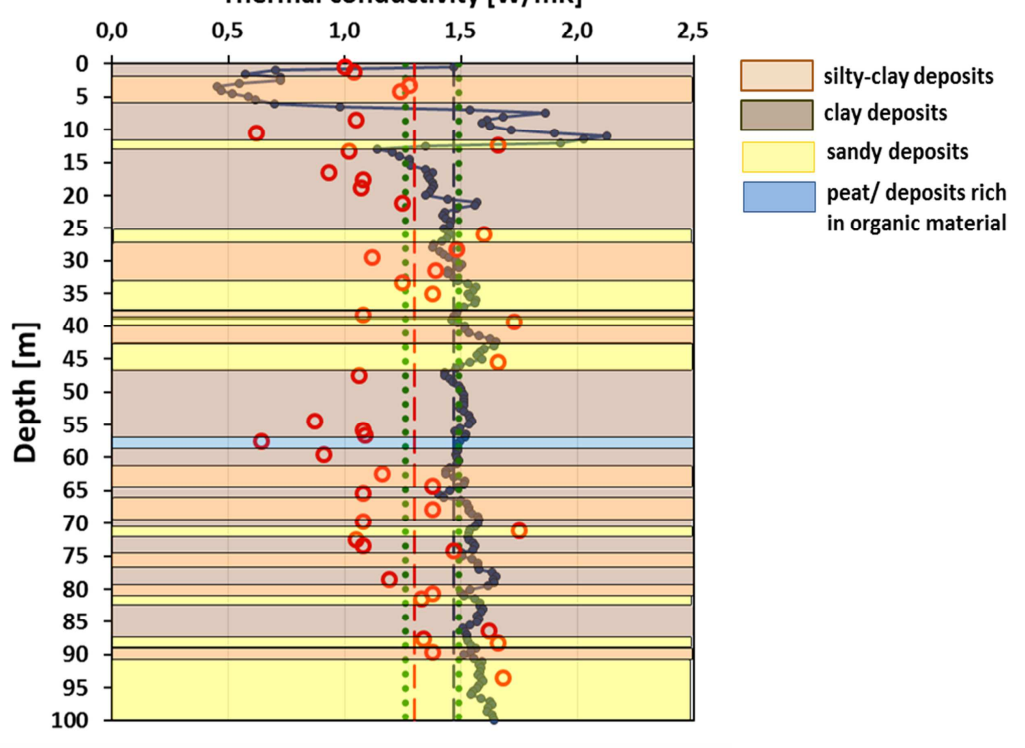

Figure 4 a) An example of fitting of the experimental data obtained from DTS used to calculate the thermal conductivity of each measurement point to determine the thermal behaviour of the surrounding sediments; b) The comparison between the thermal conductivity values obtained by analysing the DTRT data from the fibre optic cable (blue line) and the ones directly measured on the samples (red circles). The stratigraphy is represented by colours as described in the legend.

\section{CONCLUSIONS}

The results obtained highlight the potentiality of DTRT to estimate the vertical profile of thermal conductivity at low cost and not just a global value. While the thermal conductivities directly measured follow the stratigraphy succession (with higher values for sandy deposits and lower values for the cohesive ones), the profile obtained from the DTRT shows less concordance. It could be due to scale effects, to the vertical spatial average of the signal performed by the DTRT and to the penetration of grout into the deposits. In the shallower layers the outcomes are affected by external influences, while the results appear to be more stable in the deeper deposits.

Additional tests with longer heating periods performed in different seasonal conditions and in different geological conditions have been planned to provide new data and observations about the influence of some of the aforementioned perturbing factors.

Further development of the analysis method, currently on-going, will allow the interpretation of the recovery phase and the evaluation of the relationship between the stratigraphic units and the thermal conductivity measured by the DTRT. 


\section{ACKNOWLEDGMENTS}

The coring of the well has been funded by the "Cheap-GSHPs" project that has received funding from the European Union's Horizon 2020 research and innovation programme under grant agreement No.657982. The authors wish to thank Hydra srl -Hydraulic tools and Drilling Macbines (Molinella (Bo) - Italy) for providing the test field and their aid in the execution of the experimental measurements. The geotechnical classification of the deposits has been carried out in the Laboratory of Department ICEA at the University of Padova. Finally, Andrew Gambardello and Mattia Donà (technical officer of the ICEA Department - Geotechnical Engineering Laboratory) are gratefully acknowledged for performing the experimental tests.

\section{NOMENCLATURE}

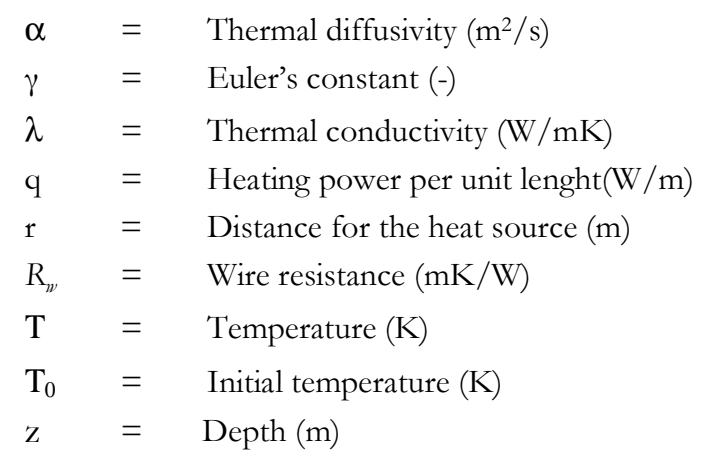

\section{Subscripts}

$\begin{array}{lll}0 & = & \text { initial } \\ w & = & \text { wire }\end{array}$

\section{REFERENCES}

ASTM International. Standard Test Method for Determination of Thermal Conductivity of Soil and Soft Rock by Thermal Needle Probe Procedure. 2000. ASTM D5334-14 ASTM International: West Conshohocken, PA, USA.

Dalla Santa, G., Galgaro, A., Tateo, F. and S. Cola. 2016. Induced Thermal Compaction in Cohesive Sediments around a Borehole Heat Exchanger: Laboratory Tests on the Effect of Pore Water Salinity. Environmental Earth Sciences, 75(3): 1-11. doi: 10.1007/s12665-015-4952-z.

Dalla Santa, G., Galgaro, A., Tateo, F. and S. Cola. 2016. Modified Compressibility of Cohesive Sediments Induced by Thermal Anomalies due to a Borehole Heat Exchanger. Engineering Geology 202 :143-152. doi: 10.1016/j.enggeo.2016.01.011.

Dalla Santa, G., Peron, F., Galgaro, A., Cultrera, M., Bertermann, D., Mueller, J. and A. Bernardi. 2017. Laboratory Measurements of Gravel Thermal Conductivity: an Update Methodological Approach. Energy Procedia 125:671-677. doi: 10.1016/ j.egypro.2017.08.287.

Dalla Santa, G., Cola, S., Secco, M., Tateo, F., Sassi, R., and A. Galgaro. 2018. Multiscale analysis of freeze-than effects induced by ground heat exchangers on permeability of silty clays. Géotechnique, 1-11. Doi: 10.1680/jgeot.16.P.313

Galgaro, A., Dalla Santa, G., Cultrera, M., Bertermann, D., Mueller, J., De Carli, M., ... and A Bernardi. 2017. EU Project "Cheap-GSHPs": The Geoexchange Field Laboratory. Energy Procedia 125: 511-519. doi: 10.1016/j.egypro.2017.08.175.

Gehlin, S. and J. D., Spitler. 2001. Thermal Response Test - State of the Art. Report IEA - ECES.

Gehlin S. and B. Nordell 2003. Determining Unidsturbed Ground Temperature for Thermal Response Test. ASHRAE 2003 Winter Meet. CD, Chicago, IL; United States. 
Ingersoll, L., Zobel, O., Ingersoll, A. 1954. Heat Conduction with Engineering, Geological and Other Applications. New York, USA: McGraw-Hill.

Isomet. Portable Heat Transfer Analyser. Available online: http://appliedp.com/produkty/isomet/(accessed on 29 November 2017).

Low, J.E., Loveridge, F.A., Powrie, W. and D. Nicholson. 2015. A comparison of laboratory and in situ methods to determine soil thermal conductivity for energy foundations and other ground heat exchanger applications. Acta geotechnica, 10(2):209-218.

Lucia, U., Simonetti, M., Chiesa, G. and G. Grisolia. 2017. Ground-source Pump System for Heating and Cooling: Review and Thermodynamic Approach. Renewable and Sustainable Energy Reviews 70: 867-874.

Popov, Y.A., Pribnow, D.F.C., Sass, J.H., Williams, C.F. and H. Burkhardt. 1999. Characterization of rock thermal conductivity by high-resolution optical scanning. Geothermics 28:253-276.

Sarbu, L. and C. Sebarchievici. 2014. General Review of Ground-Source Heat Pump Systems for Heating and Cooling of Buildings. Energy and Buildings 70: 441-454.

Selker, J.S., Thévenaz, L., Huwald, H., Mallet, A., Luxemburg, W., Van De Giesen, N. ... and M.B. Parlange. 2006. Distributed fiber-optic temperature sensing for hydrologic systems. Water Resources Research, 42(12).

Schenato, L. 2017. A review of distributed fibre optic sensors for Geo-Hydrological applications. Applied Sciences 7(9), 896; doi:10.3390/app7090896

Soto, M., Ramìrez J. A. and Thévenaz, L. 2016. Intensifying the response of distributed optical fibre sensors using $2 \mathrm{D}$ and 3D image restoration. Nature Communications 7:10870. doi:10.1038/ncomms10870.

Tarnawski, V.R.., McCombie, M.L., Momose, T., Sakaguchi, I. and W.H., Leong. 2013. Thermal Conductivity of Standard Sands. Part III. Full Range of Saturation. International Journal of Thermophysics 34: 1130-1147.

Verein Deutscher Ingenieure-VDI. VDI 4640 Part 1. In Thermal Use of the Underground: Fundamentals, Approvals, Environmental Aspects; Verein Deutscher Ingenieure: Düsseldorf, Germany, 2010

Vieira, A., Alberdi-Pagola, M., Christodoulides, P., Javed, S., Loveridge, F., Nguyen, F., ... and G. V. Lysebetten. 2017. Characterisation of Ground Thermal and Thermo-Mechanical Behaviour for Shallow Geothermal Energy Applications. Energies 10(12): 2044.

Zarrella, A., Emmi, G., Graci, S., De Carli, M., Cultrera, M., Dalla Santa, G., Galgaro, A., Bertermann, D., Mueller, J. Pockelé, L., Mezzasalma, G., Righini, D., Psyk, M. and A. Bernardi. 2017. Thermal Response Testing Results of Different Types of 2 Borehole Heat Exchangers: an Analysis and 3 Comparison of Interpretation Methods. Energies $10,801$. doi:10.3390/en10060801. 